Tropical Journal of Pharmaceutical Research December 2017; 16 (12): 2991-2996

ISSN: 1596-5996 (print); 1596-9827 (electronic) (1) Pharmacotherapy Group, Faculty of Pharmacy, University of Benin, Benin City, 300001 Nigeria.

\title{
Effect of high-dose finasteride combined with trans- urethral plasmakinetic resection of prostate on prostate- specific antigen and inflammatory factors in patients with benign prostatic hyperplasia
}

\author{
Zhe Liu*, Jia Chen, Qiang Lu \\ Department of Urology, Hunan Provincial People's Hospital, Chang Sha 410005, China \\ *For correspondence: Email: ag0696@163.com
}

Sent for review: 28 September 2017

Revised accepted: 30 November 2017

\begin{abstract}
Purpose: To ascertain the effect of perioperative application of high-dose of finasteride on prostatespecific antigen (PSA) in serum, tumor necrosis factor $\alpha$ (TNF- $\alpha)$ and interleukin-1 $\beta$ (IL-1 $\beta)$ in prostatic fluid of prostatic hyperplasia $(B P H)$ patients with transurethral plasmakinetic resection of prostate (PKRP).

Methods: In total, $141 \mathrm{BPH}$ patients treated with PKRP in Hunan Provincial People's Hospital, Changsha City, China from January 2015 to January 2017 were randomly divided into three groups of 47 cases each, viz, high-dose (10 mg of finasteride), low-dose (5 mg of finasteride), control (0 mg of finasteride). The levels of PSA in serum, as well as the levels of TNF- $\alpha$ and IL-1 $\beta$ in prostatic fluid were evaluated 7 days before and after surgery. Re-bleeding within 3 months after surgery in the three groups were performed and the patients observed.

Results: Intra-operative bleeding volume, bleeding volume per unit resected tissue, and intra-operative volume of rinsing fluid were significantly less in high- and low-dose groups than those in the control group ( $p<0.05)$; furthermore, the operation time was significantly shorter than that for the control group $(p<0.05)$. Seven days after surgery, international prostate symptom score (IPSS), serum PSA, and $T N F-\alpha$ and IL-1 $\beta$ in prostatic fluid of the high- and low-dose groups were significantly lower than those of the control group $(p<0.05)$. Also, maximum urine flow rate was significantly higher than that of the control group. Serum PSA, and TNF- $\alpha$ and IL-1 $\beta$ levels in prostatic fluid were significantly lower than those of low-dose group ( $p<0.05)$. Serum PSA as well as TNF- $\alpha$ and IL-1 $\beta$ levels in prostatic fluid were positively correlated with IPSS score $(r=0.817,0.838,0.859, p<0.001)$. The admission rate due to rebleeding was lowest in the high-dose group, followed by the low-dose group.

Conclusion: Finasteride combined with PKRP for BPH acts synergistically to reduce serum PSA levels and local inflammatory reaction. High-dose finasteride/PKRP combination is more efficacious than the low-dose combination, thereby improving short-term prognosis in patients.
\end{abstract}

Keywords: Finasteride, Transurethral plasmakinetic resection, Prostate, Prostate-specific antigen, Inflammatory factors

This is an Open Access article that uses a funding model which does not charge readers or their institutions for access and distributed under the terms of the Creative Commons Attribution License (http://creativecommons.org/licenses/by/4.0) and the Budapest Open Access Initiative (http://www.budapestopenaccessinitiative.org/read), which permit unrestricted use, distribution, and reproduction in any medium, provided the original work is properly credited.

Tropical Journal of Pharmaceutical Research is indexed by Science Citation Index (SciSearch), Scopus, International Pharmaceutical Abstract, Chemical Abstracts, Embase, Index Copernicus, EBSCO, African Index Medicus, JournalSeek, Journal Citation Reports/Science Edition, Directory of Open Access Journals (DOAJ), African Journal Online, Bioline International, Open-J-Gate and Pharmacy Abstracts 


\section{INTRODUCTION}

Benign prostate hyperplasia (BPH) is one of the common diseases in middle-aged males. The number of cases is increasing every year in tandem with rapid increase in number of aging people worldwide [1,2]. Transurethral plasmakinetic resection of prostate (PKRP) is a new surgical technique that has emerged in recent years [3]. Compared with the traditional transurethral resection of prostate, PKRP effectively reduces bleeding and transurethral resection syndrome [4], and so it is currently one of the reliable regimes for $\mathrm{BPH}$.

Previous studies [5] considered the possibility that intraoperative and postoperative bleeding would occur easily in PKRP, which would affect the prognosis of patients, but finasteride was introduced to inhibit neovascularization and reduce blood flow in $\mathrm{BPH}$, thereby preventing bleeding $[6,7]$. Thus, it was recommended that this drug should be used in the perioperative period. However, the effectiveness of finasteride in BPH treatment is associated with its inhibition of angiogenesis, and negative its effect on local anti-inflammatory agents $[8,9]$. However there are few reports on the impact of administration of finasteride in the perioperative period on the serum levels of inflammatory factors of patients.

Another impediment to the current use of finasteride is the issue of the dose regime of the drug in the perioperative period which has not been fully standardized. Furthermore, the best dose of the drug to be administered has not been made clear. On account of these shortcomings, a randomized controlled investigation was conducted in this study to unravel the curative effect of different doses of finasteride combined with PKRP in treating $\mathrm{BPH}$, and its impact on prostate specific antigen (PSA) and serum inflammatory factors.

\section{EXPERIMENTAL}

\section{General information}

The study was conducted in 141 patients with $\mathrm{BPH}$ treated in Hunan Provincial People's Hospital from January 2015 to January 2017. The study was approved by the Ethics Committee of Hunan Provincial People's Hospital (approval no. 20141201), and followed the guidelines of Declaration of Helsinki [10]. The study randomly divided all the patients into three groups, each of 47 patients. The high dose group received high finasteride dose, while the lowdose group received a lower dose of finasteride.
The control group patients were not given finasteride.

\section{Inclusion criteria}

(1) Patients diagnosed as having BPH based on the standard "Guidelines for Diagnosis and Treatment of Urological Diseases of China (2014 version)" [11]; (2) Patient who presented evidence of PKRP, and agreed to be treated surgically; (3) Patients who did not receive antiandrogen drugs for the treatment of $\mathrm{BPH}$ within the previous 6 months; (4) Patients who had been informed of this study and had signed the "Informed Consent". All those who satisfied these criteria were accepted as subjects in this study.

\section{Exclusion criteria}

(1) Patients with uncorrected hypertension and diabetes; (2) Patients with abnormality in four blood coagulation indices; (3) Patients with unstable bladder; (4) Patients allergic to related drugs were excluded.

\section{Therapeutic regimen}

Patients in the two groups were operated by the same surgeon, and sustained epidural anesthesia was used. The Gyrus bipolar plasma continuous irrigation resectoscope with a cutting power of 200W and electrocoagulation power of $100 \mathrm{~W}$ was used as the main equipment. Normal saline was used as irrigation fluid. The resectoscope was inserted into the urethra. The urethra, prostate and surrounding tissue morphology were first examined. The resection was carried out from the median lobe or the lateral lobe of the prostate, guided by the bladder neck and colliculus seminalis. The depth of the resection reached the circular fiber of the prostate capsule. Post-operative conventional indwelling catheter was used. The high-dose group received $10 \mathrm{mg}$ of finasteride (Liaoning Yuhuang Pharmaceutical Co., Ltd.; SFDA approval no: H20061299; 5 mg/tablet) twice daily continuously at 7 days before and 7 days post-surgery. The low-dose group received $5 \mathrm{mg}$ finasteride daily continuously at 7 days before and 7 days after the surgery, while the control group did not receive finasteride.

\section{Observation indices}

\section{Surgical results}

These include operation time, intra-operative blood loss, weight of resected prostate, the amount of bleeding per unit of resected tissue, bleeding rate, amount of intraoperative rinsing 
fluid (where the amount of bleeding per unit tissue $=$ intraoperative blood loss/weight of resected prostate), and bleeding rate (intraoperative blood loss/operation time).

\section{Clinical efficacy}

The international prostate symptom score (IPSS) [12] and the maximum urinary flow rate of patients in the two groups were measured at 7 days before and after surgery.

\section{Changes in PSA and inflammatory factors}

The peripheral blood and prostatic fluid of the patients were collected before the first administration of finasteride, at 7 days before the surgery and after the last administration of the drug, and at 7 days after the surgery. The levels of serum PSA were measured by enzyme-linked immunosorbent assay (ELISA), using assay kits (American DPC (USA). Radioimmunoassay was employed to determine levels of TNF- $\alpha$ and IL-1 $\beta$ in prostatic fluid using an assay kit (Beijing North Institute of Biological Technology (China). Rebleeding situations after surgery were investigated within 3 months in the 2 groups.

\section{Statistical methods}

Data obtained were expressed as mean \pm standard deviation, and were tested for significance by paired t- test, one-way analysis of variance (ANOVA) and SNK- $q$ test. The analyses were done with SPSS 19.0 software. Constituent ratios were tested by chi-square test. Correlation analysis was performed by Pearson method. Differences between mean values were considered significant at $p<0.05$.

\section{RESULTS}

\section{Baseline data for the three groups}

There were no significant differences in baseline data such as age, prostate volume, maximum urinary flow rate and underlying disease complications among the three groups $(p>0.05)$. These baseline data were comparable as shown in Table 1.

\section{Surgical results}

The weight of resected prostate and bleeding rate among the three groups showed no statistically significant differences $(p>0.05)$. Intraoperative blood loss, blood loss per unit resected tissue and the amount of intraoperative rinsing fluid were significantly lower in the highand the low-dose group than those in the control group $(p<0.05)$. In addition, the operation time was significantly shorter in the high-dose group than that in the control group $(p<0.05)$, but there was no significant difference in these indices between the high- and the low-dose group $(p>$ 0.05; Table 2).

Table 1: Baseline data for the three experimental groups (mean \pm SD)

\begin{tabular}{|c|c|c|c|c|c|c|}
\hline \multirow[b]{2}{*}{ Group } & \multirow[b]{2}{*}{ Age (year) } & \multirow{2}{*}{$\begin{array}{c}\text { Prostate } \\
\text { volume (ml) }\end{array}$} & \multirow{2}{*}{$\begin{array}{l}\text { Maximum } \\
\text { urinary flow } \\
\text { rate }(\mathrm{ml} / \mathrm{s})\end{array}$} & \multicolumn{3}{|c|}{ Complicated with underlying diseases } \\
\hline & & & & Hypertension & $\begin{array}{c}\text { Coronary heart } \\
\text { disease }\end{array}$ & Diabetes \\
\hline High-dose (47) & $67.15 \pm 5.51$ & $57.16 \pm 11.97$ & $6.83 \pm 2.17$ & $15(31.91 \%)$ & $8(17.02 \%)$ & $12(25.53 \%)$ \\
\hline Low-dose (47) & $66.32 \pm 6.12$ & $58.55 \pm 9.72$ & $6.55 \pm 2.36$ & $12(25.53 \%)$ & $10(21.28 \%)$ & $10(21.28 \%)$ \\
\hline Control (47) & $68.68 \pm 5.86$ & $56.23 \pm 9.54$ & $7.11 \pm 1.95$ & $16(34.04 \%)$ & $10(21.28 \%)$ & $12(25.53 \%)$ \\
\hline$F / X^{2}$ & 1.980 & 0.586 & 0.783 & 0.870 & 0.357 & 0.310 \\
\hline$P$ & 0.142 & 0.558 & 0.459 & 0.647 & 0.837 & 0.856 \\
\hline
\end{tabular}

Table 2: Surgical results for the three groups (mean \pm SD)

\begin{tabular}{|c|c|c|c|c|c|c|}
\hline Group & $\begin{array}{l}\text { Operation } \\
\text { time } \\
(\mathrm{min})\end{array}$ & $\begin{array}{l}\text { Intraoperative } \\
\text { blood loss } \\
\text { (ml) }\end{array}$ & $\begin{array}{l}\text { Weight of } \\
\text { resected } \\
\text { prostate } \\
\text { (g) }\end{array}$ & $\begin{array}{l}\text { Blood loss } \\
\text { per unit } \\
\text { resected } \\
\text { tissue } \\
(\mathrm{ml} / \mathrm{g})\end{array}$ & $\begin{array}{l}\text { Bleeding } \\
\text { rate } \\
(\mathrm{ml} / \mathrm{min})\end{array}$ & $\begin{array}{l}\text { Amount of } \\
\text { intraoperative } \\
\text { rinsing fluid } \\
\text { (L) }\end{array}$ \\
\hline High-dose (47) & $52.19 \pm 14.49$ & $99.38 \pm 12.30$ & $28.19 \pm 4.34$ & $3.00 \pm 1.74$ & $1.86 \pm 0.74$ & $17.11 \pm 4.96$ \\
\hline Low-dose (47) & $52.79 \pm 15.30$ & $100.94 \pm 15.50$ & $28.42 \pm 4 . .44$ & $3.48 \pm 1.86$ & $1.60 \pm 0.80$ & $17.11 \pm 7.16$ \\
\hline Control (47) & $81.89 \pm 18.67$ & $148.66 \pm 21.69$ & $28.62 \pm 5.15$ & $5.81 \pm 2.56$ & $1.64 \pm 0.83$ & $23.06 \pm 5.16$ \\
\hline$F$ & 51.269 & 128.346 & 0.099 & 24.548 & 1.466 & 16.248 \\
\hline$p$ & 0.000 & 0.000 & 0.906 & 0.000 & 0.234 & 0.000 \\
\hline
\end{tabular}




\section{Clinical efficacy}

The IPSS scores of all the patients at 7 days after surgery were significantly lower than those at 7 days before surgery, and the maximum flow rate at 7 days after the surgery was significantly higher than that at 7 days before the surgery; the inter-group difference was statistically significant $(p<0.05)$. The difference in IPSS scores and the maximum flow rate at 7 days before the surgery among three groups showed no statistical significance $(p>0.05)$. The IPSS scores of the high- and the low-dose group were significantly lower than those of the control group and the maximum flow rate was significantly higher than that of the control group at 7 days after the surgery $(p<0.05)$, but the difference between the high- and low-dose groups showed no statistically significance $(p>0.05$; Table 3$)$.

\section{Changes in PSA, TNF- $\alpha$ and IL-1 $\beta$}

The PSA in serum, and levels of TNF- $\alpha$ and IL$1 \beta$ in prostatic fluid were significantly decreased among three groups at 7 days after surgery $(p<$ 0.05). The PSA in serum, and the levels of TNF$\alpha$ and IL-1 $\beta$ at 7 days before the surgery were not significantly different among the three groups $(p>0.05)$. The level of PSA in serum and TNF- $\alpha$ and IL-1 $\beta$ at 7 days after the surgery in the highdose group were the lowest, followed by the lowdose group, while the levels in the control group were the highest. The PSA values, and levels of TNF- $\alpha$ and IL-1 $\beta$ in the high- and low-dose groups 7 days after surgery were statistically significantly different from each other $(p<0.05$, Table 4).

\section{Correlation analysis of PSA in serum, TNF- $\alpha$ and IL-1 $\beta$ in prostatic fluid and IPSS scores}

Data obtained from 141 patients before and after surgery were included in this analysis. Pearson correlation analysis showed that PSA in serum, TNF-aand IL-1 $\beta$ in prostatic fluid were significantly positively correlated with IPSS scores $(r=0.817,0.838,0.859$; all $p<0.001)$. The scattergrams showing the lines of best fit are shown in Figure 1.

\section{Admission rate due to re-bleeding within 3 months post-surgery}

There were 2, 8 and 18 cases in the high-dose group, low-dose group and control group, respectively, due to re-bleeding within 3 months after surgery. The hospitalization rates were $4.26,17.02$ and $38.30 \%$, respectively. The rate of re-bleeding in the high-dose group was significantly lower than that of the other two groups $\left(x^{2}=4.100,16.929 ; p<0.05\right)$, while the rate of re-bleeding in the low-dose group was significantly lower than that of the control group $\left(x^{2}=5.632\right.$, all $\left.p<0.05\right)$.

\section{DISCUSSION}

Hemorrhage is the main complication of PKRP $[13,14]$. The intraoperative blood loss of the three groups in this study were $99.38 \pm 12.30 \mathrm{ml}$,

Table 3: Clinical efficacy of treatment in the three groups (mean \pm SD)

\begin{tabular}{lcccc}
\hline \multirow{2}{*}{ Group } & \multicolumn{2}{c}{ IPSS score } & \multicolumn{2}{c}{ Maximum flow rate (ml/s) } \\
\cline { 2 - 5 } & $\begin{array}{c}\text { 7 days before } \\
\text { surgery }\end{array}$ & $\begin{array}{c}\text { 7 days after } \\
\text { surgery }\end{array}$ & $\begin{array}{c}\text { 7 days before } \\
\text { surgery }\end{array}$ & 7 days after surgery \\
\hline High-dose group (47) & $24.23 \pm 6.59$ & $6.68 \pm 1.49^{\# \#}$ & $6.59 \pm 1.75$ & $28.47 \pm 4.78^{* \#}$ \\
Low-dose group (47) & $23.96 \pm 4.56$ & $6.26 \pm 1.86^{\# \#}$ & $6.05 \pm 1.57$ & $29.14 \pm 4.94^{* \#}$ \\
Control group (47) & $24.87 \pm 5.7$ & $7.98 \pm 1.44^{\#}$ & $6.50 \pm 1.44$ & $23.53 \pm 4.23^{\#}$ \\
$F$ & 0.329 & 14.678 & 1.583 & 20.297 \\
$P$ & 0.720 & 0.000 & 0.209 & 0.000 \\
\hline
\end{tabular}

Note: Compared with the control group, $p<0.05 ;^{\#}$ compared with that at 7 days before surgery, $p<0.05$

Table 4: Changes in PSA, TNF-aand IL-1 $\beta$ for the three groups (mean \pm SD)

\begin{tabular}{|c|c|c|c|c|c|c|}
\hline \multirow[t]{2}{*}{ Group } & \multicolumn{2}{|c|}{ PSA in serum (ng/ml) } & \multicolumn{2}{|c|}{ TNF-ain prostate fluid (pg/ml) } & \multicolumn{2}{|c|}{ IL-1 (pgprostate fluid (pg/ml) } \\
\hline & $\begin{array}{l}7 \text { days } \\
\text { before } \\
\text { surgery }\end{array}$ & $\begin{array}{c}7 \text { days after } \\
\text { surgery }\end{array}$ & $\begin{array}{c}7 \text { days } \\
\text { before } \\
\text { surgery }\end{array}$ & $\begin{array}{c}7 \text { days after } \\
\text { surgery }\end{array}$ & $\begin{array}{c}7 \text { days before } \\
\text { surgery }\end{array}$ & $\begin{array}{c}7 \text { days after } \\
\text { surgery }\end{array}$ \\
\hline High-dose (47) & $10.06 \pm 1.29$ & $2.67 \pm 0.53^{\#}{ }_{\Delta}$ & $66.05 \pm 17.26$ & $3.24 \pm 0.50^{* \#} \Delta$ & $4.33 \pm 0.45$ & $0.79 \pm 0.12^{\#}{ }_{\Delta}$ \\
\hline Low-dose (47) & $10.17 \pm 1.05$ & $3.41 \pm 0.38^{\pi \#}$ & $69.24 \pm 15.97$ & $4.66 \pm 0.54^{\pi \#}$ & $4.24 \pm 0.36$ & $1.21 \pm 0.08^{\star \#}$ \\
\hline Control (47) & $10.02 \pm 1.22$ & $5.41 \pm 0.77^{\#}$ & $67.60 \pm 16.25$ & $8.40 \pm 1.32^{\#}$ & $4.24 \pm 0.25$ & $1.46 \pm 0.15^{\#}$ \\
\hline$F$ & 0.186 & 279.479 & 0.440 & 436.308 & 0.949 & 359.377 \\
\hline$p$ & 0.831 & 0.000 & 0.645 & 0.000 & 0.390 & 0.000 \\
\hline
\end{tabular}

Compared with the control group, $p<0.05 ;{ }^{\Delta}$ compared with low-dose group, $p<0.05 ;{ }^{\#}$ compared with that at 7 days before surgery, $p<0.05$ 

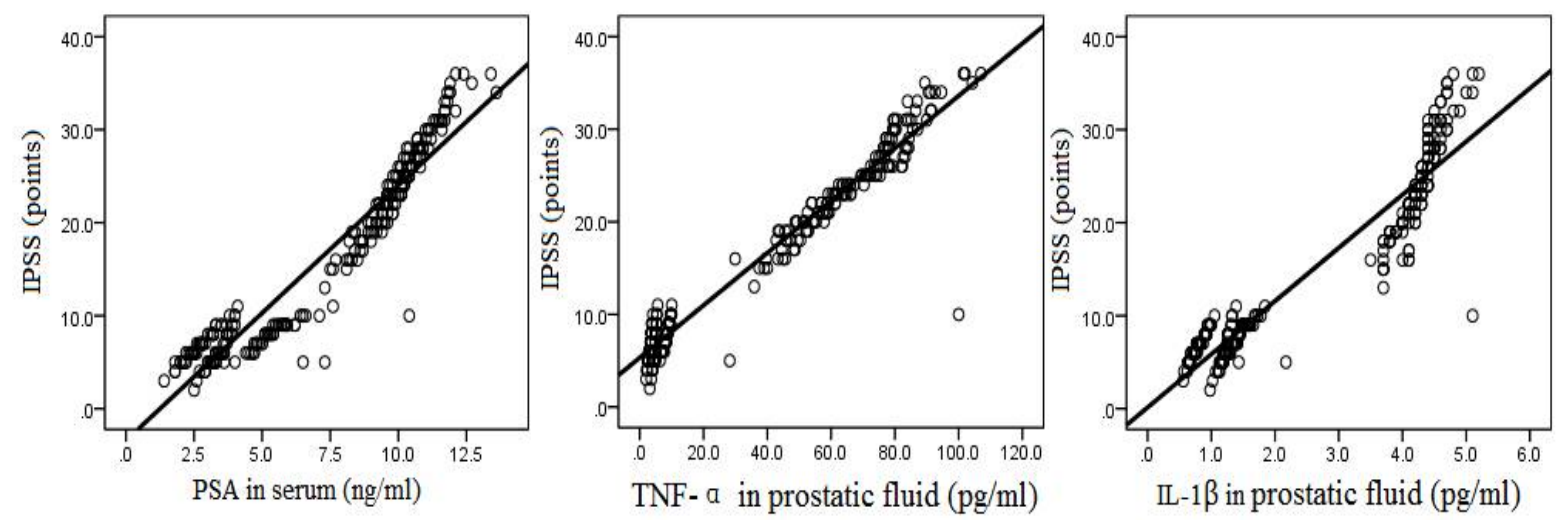

Figure 1: Scattergram of IPSS scores and PSA in serum, TNF-aand IL-1 $\beta$ in prostatic fluid

$100.94 \pm 15.50 \mathrm{ml}$, and $148.66 \pm 21.69 \mathrm{ml}$ respectively, which are smaller in volume when compared to the intraoperative blood loss reported by Zhouliang et al [15] and Xiaowei et al [16].

The values they reported were $210.45 \pm 19.17 \mathrm{ml}$ and $231.38 \pm 77.52 \mathrm{ml}$ respectively. The causes of bleeding include bladder spasm, incomplete hemostasis and residual glands [17], which cannot be completely avoided even with improved surgical skills. Hence there is need to take auxiliary measures that will ensure that bleeding is prevented completely or in the event of re-bleeding, that it is reduced to the barest minimum.

Multiple studies [18,19] have revealed that treatment of patients with finasteride perioperatively helps to reduce intraoperative and post-operative blood losses. The results of this study were in accord with the earlier findings $[18,19]$. Finasteride at the doses used in the present study (5 mg/day or $10 \mathrm{mg} /$ day) can reduce the intraoperative blood loss and blood loss due to tissue excision. Due to the low blood loss, the operative field was clearer, which accounted for the fact that the operation times in the high and high-dose groups were significantly shorter than that of the control group. This is consistent with the result obtained by Liuyu et al [20].

The protective effect of finasteride on intraoperative bleeding could be attributed to its inhibitory effect on the activity of vascular endothelial growth factor: androgens have stimulatory effect on vascular endothelial growth factor, and can increase prostate blood flow [21]. Finasteride can, by selectively and competitively inhibiting $5 a$ reductase type II, block testosterone conversion to dihydrotestosterone (DHT). This reduces the level of active androgen, and is accompanied by reduced prostate blood flow. A previous report [22] also showed that finasteride can directly reduce the level of vascular endothelial growth factor (VEGF) in the kidney and the microvessel density.

However, finasteride has other mechanisms of action on BPH. For example, Wuchengzhang et al [23] found that finasteride when administered to elderly patients with $\mathrm{BPH}$ can reduce the levels of serum TNF- $\alpha$ and PSA, which explained the fact that treatment with finasteride can relieve systemic inflammation and overexpression of PSA. It further shows that treatment of patients with finasteride in perioperative period can also reduce the levels of PSA and inhibit inflammation. The present study found that the PSA in serum, TNF- $\alpha$ and IL- $1 \beta$ in the high-dose groups were significantly lower than that of the control group, which gives credence to the foregoing hypothesis, and also lends weight to the view that finasteride when combined with PKRP can be the best and safest strategy for the management/ treatment of BPH.

Current studies on the use of finasteride in perioperative period for the reduction of bleeding in BPH surgery are yet to be conclusive. There are differences in the doses and duration of use in various reports. For example, Shenjun et al [24] holds the opinion that finasteride should be used for a long time before surgery while Dengguangpeng et al [25] believe that treatment with high-dose of finasteride at 7 days before surgery could improve the surgical outcome. On the basis of the foregoing opinions and the findings from this study it does appear that: (a) surgery may not produce complete curative effect on BPH, and (b) continuous application of finasteride after surgery may enhance the curative effect.

Thus, finasteride was applied 7 days before and after surgery, both in low and high-dose group in this study, and the results confirmed that the two 
regimens improved the surgical outcome: the low levels of PSA and inflammatory factor observed in the high-dose group are remarkable, and suggest that this treatment strategy can bring about improved BPH prognosis. The low rate of re-bleeding admission after surgery as found in this study in the high-dose group is also indicative of better prognosis, which is consistent with previous reports $[26,27]$.

\section{Limitations of the study}

The sample size in this study is limited. Furthermore, the effect of the specific mechanism action of different doses of finasteride on PSA, TNF- $\alpha$ and IL- $1 \beta$ levels in BPH patients after PKRP is yet to be elucidated. Therefore, randomized trials based on a larger sample size are needed to further study.

\section{CONCLUSION}

Finasteride, when combined with PKRP in the treatment of $\mathrm{BPH}$ further reduces serum PSA and local inflammatory factors. The effect is more pronounced in patients treated with higher dose of finasteride. The combination therapy is thus a better management strategy for $\mathrm{BPH}$.

\section{DECLARATIONS}

\section{Conflict of interest}

No conflict of interest is associated with this work.

\section{Contribution of authors}

We declare that this work was done by authors named in this article and all liabilities pertaining to claims relating to the content of this article will be borne by them. All the authors read and approved the manuscript for publication. Zhe Liu conceived and designed the study, Jia Chen collected and analysed the data, Qiang Lu wrote the manuscript.

\section{REFERENCES}

1. Mobley $D$, Feibus A, Baum N. Benign prostatic hyperplasia and urinary symptoms: Evaluation and treatment. Postgrad Med 2015; 127(3): 301-307.

2. Bechis SK, Otsetov AG, Ge R, Olumi AF. Personalized medicine for the management of benign prostatic hyperplasia. J Urol 2014; 192(1): 16-23.

3. Zhu L, Chen $S$, Yang $S$, Wu $M$, Ge R, Wu W. Electrosurgical enucleation versus bipolar transurethral resection for prostates larger than $70 \mathrm{ml}$ : a prospective, randomized trial with 5-year followup. J Urol2013; 189(4): 1427-1431.

4. Stucki $P$, Mattei A, Marini L, Xafis $K$, Danuser $H$, Stucki $P$, Mattei A, Marini L, Xafis K, Danuser H. Bipplar Versus Monopolar Transurethral Resection of the Prostate: A Prospective Randomized Trial Focusing on Bleeding Complications. J Urol 2015; 193(4): 13711374.

5. Khwaja MA, Nawaz G, Muhammad S, Jamil MI, Faisal M, Akhter S. The Effect of Two Weeks Preoperative Finasteride Therapy in Reducing Prostate Vascularity. J Coll Physicians Surg Pak 2016; 26(3): 213-215.

6. Jiang $Y$, Long $Y F$. [Effects of finasteride on hematuria associated with benign prostatic hyperplasia: a metaanalysis]. Nat J Androl 2010; 16(8): 726-729.

7. Zong HT, Peng XX, Yang CC, Zhang Y. A systematic review of the effects and mechanisms of preoperative $5 \alpha$-reductase inhibitors on intraoperative haemorrhage during surgery for benign prostatic hyperplasia. Asian $J$ Androl 2011; 13(6): 812-815.

8. Kaplan SA, Lee JY, Meehan AG, Kusek JW, Group M. Long-term treatment with finasteride improves clinical progression of benign prostatic hyperplasia in men with an enlarged versus a smaller prostate: data from the MTOPS trial. J Urol 2011; 185(4): 1369-1372.

9. Bauman TM, Sehgal PD, Johnson KA, Pier T, Bruskewitz $R C$, Ricke WA, Huang W. Finasteride treatment alters tissue specific androgen receptor expression in prostate tissues. Prostate 2014; 74(9): 923-932.

10. Williams JR. The Declaration of Helsinki and public health. Bull World Health Organ 2008; 86(8): 650-654.

11. Na Y. Guidelines for the Diagnosis and Treatment of Urology in China. Peking: People's Medical Publishing House 2014: 54(3): 252-256.

12. Bayoud Y, Taille A, Ouzzane A, Ploussard G, Allory $Y$, Yiou R, Vordos $D$, Hoznek A, Salomon L. International Prostate Symptom Score is a predictive factor of lower urinary tract symptoms after radical prostatectomy. Int $\mathrm{J}$ Urol 2015; 22(3): 283-287.

13. Liu C, Zheng S, Li H, Xu K. Transurethral enucleation and resection of prostate in patients with benign prostatic hyperplasia by plasma kinetics. J Urol 2010; 184(6): 2440-2445.

14. Yee CH, Wong HM, Chiu KF, Teoh YC, Chan CK, Chan SY, Hou SM, Ng CF. Secondary hemorrhage after bipolar transurethral resection and vaporization of prostate. Urol Ann 2016; 8(4): 458-463.

15. Liang Zhou ZH. Impact of transurethral resection on the urethral stricture and sexual function of patients with prostate hyperplasia. Chin J Hum Sexual 2014; 23(5): 11-14.

16. Xiao W, Yang K, Gao Z, Wu W, Yuan W, Zhou Q, Duan $Y$, Urology DO. Comparison and safety evaluation of transurethral resection of prostate versus bipolar plasmakinetic resection of the prostate in the treatment of benign prostatic hyperplasia. J Chongqing Medical University 2014; 39(1): 76-79. 
17. Sarma MVK, Kumar BM, Kumar PD. Monopolar versus bipolar transurethral resection of prostate for benign prostatic hyperplasia: Operative outcomes and surgeon preferences, a real-world scenario. Urol Ann 2016; 8(3): 291-296.

18. Aminsharifi A SA, Noorafshan A, Aminsharifi A, Alnajar K. Effect of Preoperative Finasteride on the Volume or Length Density of Prostate Vessels, Intraoperative, Postoperative Blood Loss during and after Monopolar Transurethral Resection of Prostate: A Dose Escalation Randomized Clinical Trial Using Stereolog Methods. Urol J 2016; 13(1): 2562-2568.

19. Pastore AL, Mariani S, Barrese F, Palleschi G, Valentini AM, Pacini L, Petrozza V, Carbone A, Cappa M. Transurethral resection of prostate and the role of pharmacological treatment with dutasteride in decreasing surgical blood loss. Eur Urol 2013; 27(1): 6870.

20. Liu Y, Hou TH, Jiang HM, Feng YH, Zhang L. Clinical research on preoperative application of finasteride in reducing transurethral resection syndrome. Shandong Med J 2013; 28(2): 1-3.

21. Chen YJ. Effects of androgen on vascular and inflammatory biomarkers in a female hypertensive population. Gynecol Endocrinol 2013; 29(4): 340-344.

22. Tian HL, Zhao CX, Wu HY, Xu ZX, Wei LS, Zhao RT, Jin $D L$. Finasteride Reduces Microvessel Density and
Expression of Vascular Endothelial Growth Factor in Renal Tissue of Diabetic Rats. Am J Med Sci 2015; 349(6): 516-520.

23. Chengzhang Wu SL. Effect of terazosin hydrochloride combined with finasteride on serum TNF- $\alpha$ and PSA in elderly patients with benign prostatic hyperplasia. Chin J Biochem Pharm 2016; 36(4): 97-99.

24. Jun Shen $X Y$, Guoxiang Guo, Lei Xie, Weifeng Xie, Jianjun Cui, Honghui Xia. Observation of the efficacy on bleeding of transurethral electrovaporization of the prostate by finasteride in different administrations. Chin J Med 2016; 51(1): 100-102.

25. Guangpeng Deng YW. Effect of finasteride combined with plasma kinetic resection of prostate in the treatment of patients with benign prostatic hyperplasia and its quality of life. J Guangxi Med University 2017; 37(7): 1091-1093.

26. Lim CF, Buchan NC. Measurement of serum PSA as a predictor of symptoms scored on the IPSS for patients with benign prostatic hyperplasia. N Z Med J 2014; 127(1389): 17-24.

27. Haikuan Li RW, Zengxiang Zhou. Variation characteristics of proinflammatory cytokines in patients with prostitis and benign prostatic hyperplasia. Chinese J Diffic Compl Cases 2015; 14(5): 491-493. 